\title{
PERSEPSI PEMBUDIDAYA TERHADAP PENGEMBANGAN BUDIDAYA IKAN LELE DI DESA WARUKAPAS KECAMATAN DIMEMBE KABUPATEN MINAHASA UTARA PROVINSI SULAWESI UTARA
}

\author{
Jessica V. Sorongan'; Jardie A. Andaki2; Olvie V. Kotambunan² \\ 1)Mahasiswa Fakultas Perikanan dan IImu Kelautan Universitas Sam Ratulangi Manado \\ 2) Staff Pengajar Fakultas Perikanan dan IImu Kelautan Universitas Sam Ratulangi Manado \\ Koresponden email :jessicasorongan04@gmail.com
}

\begin{abstract}
The purpose of this study was to determine the various roles of fish farmers in cultivating catfish in Warukapas Village, and to know the perceptions of fish farmers on the development of catfish cultivation in Warukapas Village.

This research method is a survey method, which is a critical observation or investigation to get good information on a particular problem in a particular area or location that is patterned to obtain the information needed. The informants were 20 respondents who sought cultivation of freshwater fish, both tilapia and catfish cultivation.

The perception of freshwater fish farmers in Warukapas Village, Dimembe Subdistrict is quite good for the development of catfish cultivation from the aspect of production. Most of the respondents (50.00\%) stated that the activity of cultivating catfish was quite good. In the consumption aspect, most of the respondents (48.75\%) perceived poorly, because people were not accustomed to consuming catfish and did not like a variety of catfish-based preparations. In the marketing aspect, the majority of respondents (61.67\%) stated that catfish marketing was not good because after the harvest the farmers had difficulty marketing the catfish.

Keywords: cultivators, catfish, development, perception
\end{abstract}

\begin{abstract}
Abstrak
Tujuan penelitian ini adalah untuk mengetahui berbagai peran pembudidaya ikan dalam membudidayakan lele di Desa Warukapas, dan mengetahui persepsi pembudidaya ikan terhadap pengembangan budidaya lele di Desa Warukapas.

Metode penelitian ini adalah metode survei,yaitu suatu pengamatan atau penyelidikan yang kritis untuk mendapatkan keterangan yang baik terhadap suatu persoalan tertentu di dalam daerah atau lokasi tertentu yang dipolakan untuk memperoleh informasi yang dibutuhkan.Informan sebanyak 20 responden yang mengusahakan pembudidayaan ikan air tawar, baik budidaya nila ataupun lele.

Persepsi pembudidaya ikan air tawar di Desa Warukapas Kecamatan Dimembe tergolong cukup baik terhadap pengembangan usaha budidaya lele dari aspek produksi. Sebagian besar responden (50,00\%) menyatakan bahwa kegiatan membudidayakan lele cukup baik. Pada aspek konsumsi sebagian besar responden (48,75\%) berpersepsi kurang baik, dikarenakan masyarakat tidak terbiasa mengkonsumsi lele dan tidak menyukai berbagai olahan berbahan dasar lele. Pada aspek pemasaran sebagian besar responden $(61,67 \%)$ menyatakan pemasaran lele kurang baik karena setelah panen para pembudidaya kesulitan memasarkan lele tersebut.

Kata kunci: pembudidaya, ikan lele, pengembangan, persepsi
\end{abstract}

\section{PENDAHULUAN}

Indonesia merupakan negara kepulauan yang memiliki potensi cukup besar untuk melakukan pengembangan budidaya ikan air tawar.Salah satu komoditas ikan air tawar yang sangat potensial ialah Lele.Lele merupakan salah satu jenis ikan air tawar yang memiliki nilai ekonomi tinggi.lkan ini sudah dibudidayakan secara komersial oleh masyarakat Indonesia.Budidaya lele berkembang pesat dikarenakan dapat dibudidayakan pada lahan dan sumber air yang terbatas dengan padat tebar tinggi, pemasarannya relatif mudah, dan modal yang dibutuhkan relatif rendah (Effendie, 2003).Pengembangan usaha budidaya Lele semakin meningkat setelah masuknya jenis Lele Sangkuriang (Clarias gariepinus) ke Indonesia pada tahun 1985. Keunggulan lele dumbo dibanding lele lokal antara laintumbuh lebih cepat, dan lebih tahan penyakit.

Perkembangan budidaya yang pesat tanpa didukung pengelolaan induk yang baik menyebabkan Lele Dumbo mengalami penurunan kualitas.Hal ini karena adanya perkawinan sekerabat (inbreeding), seleksi induk yang salah dan penggunaan induk yang berkualitas rendah. Sebagai upaya 
perbaikan mutu Lele Dumbo, Balai Pengembangan Benih Air Tawar (BPBAT) Sukabumi telah berhasil melakukan rekayasa genetik dengan cara silang balik untuk manghasilkan lele dumbo strain baru yang diberi nama Lele Sangkuriang (Nasrudin, 2010). Belakangan ini Lele Sangkuriang sangat populer di Aceh, seperti yang telah diketahui bahwa Lele Sangkuriang memiliki potensi untuk tumbuh lebih cepat dibandingkan jenis Lele lainnya.

Kabupaten Minahasa Utara merupakan salah satu kabupaten yang memiliki sumberdaya air tawar melimpah. Kondisi ini memberikan peluang pada pembuidaya ikan untuk memelihara berbagai jenis ikan. Desa Warukapas merupakan salah satu dari 11 Desa yang terdapat di Wilayah Kecamatan Dimembe yang banyak memproduksi ikan air tawar dari kegiatan budidaya.Desa ini terletak di bagian Timur Kabupaten Minahasa Utara dengan luas wilayah keseluruhan 2.464 ha, dengan pembagian wilayah untuk kampung 35 ha, ladang 790 ha, kebun 618 ha, sawah 437 ha, kolam 100 ha, dan hutan 460 ha.

Keberadaan kolam budidaya ikan sebesar 100 ha menyebabkan Desa Warukapas cukup potensial dalam menghasilkan ikan air tawar untuk keperluan konsumsi. Namun jenis ikan yang umum dibudidayakan sebagian besar dari jenis mujair, nila dan mas. Pilihan jenis ikan ini selain mudah dalam pemeliharaannya, juga permintaan akan produk budidaya perikanan air tawar ini cukup tinggi. Pilihan terhadap jenis ikan Lele, masih sebatas pemeliharaan skala kecil atau hanya mencoba-coba saja.

\section{METODE PENELITIAN}

Metode yang digunakan dalam penelitian ini adalah metode survey, suatu pengamatan atau penyelidikan yang kritis untuk mendapatkan keterangan yang baik terhadap suatu persoalan tertentu di dalam daerah atau lokasi tertentu yang dipolakan untuk memperoleh informasi yang dibutuhkan.
Penentuan informan dilakukan secara purposive, yaitu teknik untuk menentukan sampel penelitian dengan beberapa pertimbangan tertentu yang bertujuan agar data yang diperoleh nantinya bisa lebih representative (Sugiyono, 2010).Responden dipilih yang memiliki kolam dan sudah lebih dari 1 tahun mengusahakan pembudidayaan ikan air tawar, baik budidaya ikan nila, ikan lele ataupun ikan mas.

Analisis data digunakan pendekatan secara deskritif analitik, yaitu melakukan tabulasi data, perhitungan jumlah, rata-rata, nilai minimum dan maksimum.Hasil perhitungan kemudian telah dibandingkan dengan skor rata-rata dan mendapat kesimpulan tentang persepsi pembudidaya ikan air tawar terhadap pengembangan budidaya ikan lele di Desa Warukapas.

\section{HASIL DAN PEMBAHASAN}

\section{Lama Menjalankan Usaha Budidaya}

Karakteristik responden berdasarkan lama menjalankan usaha budidaya dapat diketahui berdasarkan tabel berikut.

Tabel 1. Karakteristik Responden Berdasarkan Lama Menjalankan Usaha Budidaya

\begin{tabular}{|c|c|c|r|}
\hline No. & $\begin{array}{c}\text { Lama Menjalankan } \\
\text { Usaha(tahun) }\end{array}$ & Jumlah & $\begin{array}{c}\text { Persentase } \\
(\%)\end{array}$ \\
\hline 1. & $1-3$ & 4 & 20,00 \\
\hline 2. & $4-6$ & 15 & 75,00 \\
\hline 3. & $>6$ & 1 & 5,00 \\
\hline \multicolumn{2}{|c|}{ Jumlah } & 20 & 100,00 \\
\hline
\end{tabular}

Sumber: Data Primer Tahun 2018

Berdasarkan Tabel 1 responden paling lama menjalankan usaha budidaya adalah 4-6 tahun dengan persentase sebesar $75,00 \%$. Responden yang sudah lama menjalankan usaha budidaya ikan air tawar (>6 tahun) mempunyai presentase yang paling kecil, yaitu $5,00 \%$.

Dominasi pembudidaya yang cukup berpengalaman (4-6 tahun) pada usaha budidaya ikan air tawar, dikarenakan pada 5 tahun terakhir permintaan akan ikan air tawar cukup signifikan. Hal ini dikarenakan banyaknya kuliner-kuliner yang berkembang pesat menawarkan sajian ikan bakar air 
tawar (mas dan mujair/nila), sehingga pembudidaya mampu bertahan untuk menjalankan usaha budidaya ikan air tawar.

\section{Persepsi Terhadap Aspek Produksi}

Masyarakat Desa Warukapas mempunyai minat tinggi terhadap pengembangan usaha budidaya ikan air tawar, khusus ikan mas dan mujair/nila. Budidaya lele pada hasil penelusuran di lapangan ditemukan ada pembudidaya yang melakukan baik untuk coba-coba sampai pada penjualan.Minat terhadap pengembangan usaha budidaya lele oleh pembudidaya ikan di Desa Warukapas, menjadi titik perhatian, khususnya pada aspek persepsi masyarakat pembudidaya di Desa Warukapas.

Persepsi pembudidaya terhadap aspek produksi Lele dari responden di Desa Warukapas dapat dilihat pada tabel berikut.

Tabel 2. Persepsi Pembudidaya Terhadap Aspek Produksi Lele dari responden di Desa Warukapas.

\begin{tabular}{|c|l|c|c|}
\hline No. & Persepsi & Jumlah & $\begin{array}{c}\text { Persentase } \\
(\%)\end{array}$ \\
\hline 1. & Kurang baik & 7,20 & 36,00 \\
\hline 2. & Cukup baik & 10,00 & 50,00 \\
\hline 3. & Baik & 2,80 & 14,00 \\
\hline \multicolumn{2}{|c|}{ Jumlah } & 20 & 100,00 \\
\hline
\end{tabular}

Sumber: Data Primer (2018)

Berdasarkan Tabel 2 terdapat $14,00 \%$ responden menyatakan kegiatan untuk memproduksi lele baik dan 50,00\% responden menyatakan cukup baik, dan $36,00 \%$ responden menyatakan data dan informasi persepsi pembudidaya terhadap produksi lele kurang baik.

Sebagian besar responden $(50,00 \%)$ menyatakan bahwa kegiatan membudidayakan lele cukup baik. Hal ini dikarenakan responden sering memperoleh informasi melalui sosialisasi dari BBAT (Balai Budidaya Air Tawar) Tatelu. Hasil ini sesuai dengan pernyataan Sunaryo (2004), bahwa persepsi merupakan proses akhir dari pengamatan yang diawali oleh proses pengindraan, yaitu proses diterimanya stimulus oleh alat indra, lalu diteruskan ke otak, dan baru kemudian individu menyadari tentang sesuatu yang dipersepsikan. Sedangkan Rakhmat (2004), menyatakan persepsi adalah pengalaman tentang objek, peristiwa, atau hubungan-hubungan yang diperoleh dengan menyimpulkan informasi dan melampirkan pesan.

Pada responden berpersepsi kurang baik $(36,00 \%)$, disebabkan pada kekurangtahuan terhadap aspek produksi dari ikan lele, sehingga mengurangi minat untuk mengembangkan usaha budidaya lele di Desa Warukapas. Sedangkan responden berpersepsi baik (14\%), dikarenakan responden tersebut sudah mulai mencoba melakukan usaha produksi lele berdasarkan informasi dan penyuluhan dari Dinas Perikanan.

\section{Persepsi Terhadap Konsumsi}

Persepsi masyarakat terhadap konsumsi merupakan penilaian pembudidaya terhadap penggunaan lele sebagai ikan konsumsi.Penilaian menggunakan daftar pertanyaan untuk menilai persepsi pembudidaya ikan air tawar di Desa Warukapas.

Persepsi pembudidaya ikan air tawar terhadap konsumsi lele, dapat dilihat pada tabel berikut.

Tabel 3. Persepsi Pembudidaya Ikan Air Tawar di Desa Warukapas terhadap Konsumsi

\begin{tabular}{|c|c|r|r|}
\hline No. & Persepsi & Jumlah & Persentase (\%) \\
\hline 1. & Kurang baik & 9,75 & 48,75 \\
\hline 2. & Cukup baik & 5,25 & 26,25 \\
\hline 3. & Baik & 5,00 & 25,00 \\
\hline \multicolumn{2}{|c|}{ Jumlah } & 20,00 & 100,00 \\
\hline
\end{tabular}

Sumber: Data Primer (2018)

Berdasarkan Tabel 3 terdapat $48,75 \%$ responden menyatakan bahwa pemanfaatan lele sebagai ikan konsumsi kurang baik; 26,25\% responden menyatakan cukup baik; dan 25,00\% responden menyatakan baik.

Sebagian besar responden (48,75\%) berpersepsi bahwa konsumsi lele di kurang baik, dikarenakan masyarakat tidak terbiasa mengkonsumsi lele dan tidak menyukai berbagai olahan berbahan dasar lele. Ditambah lagi masih banyak ikan utama 
yang sudah biasa dikonsumsi, yaitu ikan mas dan mujair/nila di Desa Warukapas.

Pada pembudidaya yang berpersepsi cukup baik dan baik (26,25 dan 25,\%), dikarenakan responden telah diinformasikan akan kebaikan mengkonsumsi lele dari segi nilai gizi, sanitasi, higeine, dan kesehatan. Dalam pandangan masyarakat umum, khusus di Sulawesi Utara tentang lele yang tidak layak dikonsumsi, ternyata di provinsi lain, misalnya Jawa konsumsi lele sangat tinggi dengan berbagai jenis olahan segar dan atau diawetkan

\section{Persepsi terhadap Pemasaran}

Persepsi pembudidaya ikan air tawar terhadap aspek pemasaran di Desa Warukapas, dapat dilihat pada tabel berikut.

Tabel 4. Persepsi Pembudidaya Ikan Air Tawar di Desa Warukapas terhadap Pemasaran.

\begin{tabular}{|c|l|r|r|}
\hline No. & \multicolumn{1}{|c|}{ Persepsi } & \multicolumn{1}{c|}{ Jumlah } & \multicolumn{1}{c|}{$\begin{array}{c}\text { Persentase } \\
(\%)\end{array}$} \\
\hline 1. & Kurang baik & 12,33 & 61,67 \\
\hline 2. & Cukup baik & 1,00 & 5,00 \\
\hline 3. & Baik & 6,67 & 33,33 \\
\hline \multicolumn{2}{|c|}{ Jumlah } & 20,00 & 100,00 \\
\hline
\end{tabular}

Sumber: Data Primer (2018)

Berdasarkan Tabel 4 terdapat $61,67 \%$ responden menyatakan pemasaran lele kurang baik; $33,33 \%$ responden menyatakan baik; dan $5,00 \%$ responden menyatakan cukup baik.

Sebagian besar responden $(61,67 \%)$ menyatakan pemasaran lele kurang baik. Karena setelah panen para pembudidaya kesulitan memasarkan lele tersebut. $(5,00 \%)$ responden menyatakan cukup baik terhadap pemasaran lele karena beberapa pembudidaya memiliki pembeli langganan yang biasa membeli lele yang dibudidayakan. Demikian pula ada $(33,33 \%)$ responden yang berpersepsi baik dikarenakan telah mempunyai saluran pemasaran yang baik.

Situasi atau kondisi tempat usaha terkait permintaan akan produk hasil budidaya lele sangat mempengaruhi persepsi pembudidaya terhadap pengembangan usaha lele. Hal ini sesuai dengan pendapat Robbins, (2001), menyatakan bahwa situasi dalam hal ini penting untuk melihat konteks objek atau peristiwa sebab unsur-unsur lingkungan sekitar mempengaruhi persepsi kita.

\section{KESIMPULAN}

Secara keseluruhan dapat disimpulkan bahwa persepsi pembudidaya ikan air tawar di Desa Warukapas Kecamatan Dimembe tergolong cukup baik terhadap pengembangan usaha budidaya ikan lele dari aspek produksi. Sebagian besar responden $(50,00 \%)$ menyatakan bahwa kegiatan membudidayakan ikan lele cukup baik.

Pada aspek konsumsi sebagian besar responden $(48,75 \%)$ berpersepsi kurang baik, dikarenakan masyarakat tidak terbiasa mengkonsumsi lkan lele dan tidak menyukai berbagai olahan berbahan dasar ikan lele.

Pada aspek pemasaran sebagian besar responden $(61,67 \%)$ menyatakan pemasaran ikan lele kurang baik karena setelah panen para pembudidaya ikan air tawar kesulitan memasarkan ikan lele tersebut.

\section{DAFTAR PUSTAKA}

Creswell, 2009. Research Design, Pendekatan Kualitatif, Kuantitatif, dan Mixed, (Terjemahan : Achmad Fawaid, Edisi Ketiga, Pustaka Pelajar, Yogyakarta)

Effendi, I., 2004. Pengantar Akuakultur. p.188. Jakarta: Penebar Swadaya.

Effendie, H., 2003. Telaah Kualitas Air Bagi Pengelolaan Sumberdaya dan LingkunganPerairan.Kanisius. Jakarta.

Fathoni.2006. Metodologi Penelitian dan Teknik Penyusunan Skripsi. Jakarta: PT Rineka Cipta.

Kordi, K. M. G. H. 2010. Budidaya Ikan Lele Di Kolam Terpal. Andi Offset. Yogyakarta

Lukito, A. M. 2002. Lele Ikan Berkumis Paling Populer.Agromedia. Jakarta

Moleong, L.J., 2005. Metode Penelitian Kualitatif, Bandung, Edisi Revisi, Penerbit PT Remaja Rosdakarya.

Nasrudin, 2010. Jurus Sukses Beternak Lele Sangkuriang. Jakarta: PT. Agromedia Pustaka 
AKULTURASI

Available online :http://ejournal.unsrat.ac.id/index.php/akulturasi

Rakhmat, J., 2004. Metode Penelitian Komunikasi.Bandung : Rosdakarya

Robbins, S.P., 2001. Perilaku Organisasi: Konsep, kontroversi, Aplikasi, Jilid 1, Edisi 8, Prenhalindo, Jakarta.

Sugiyoni, 2010. Metode Penelitian Kuantitatif Kualitatif \& RND. Bandung: Alfabeta.

Sukadi, M. F 2002.Peningkatan teknologi budidaya perikanan.Jurnal ikhtiologi Indonesia Vol.2, No. 2, Tahun 2002. Hal 61-66.

Sunaryo, 2004.Psikologi untuk Keperawatan.EGC. Jakarta
Supardi, M.D., 2006. Metode Penelitian Mataram: Yayasan Cerdas Press.

Tajerin, Mohammad Noor, 2005. Faktor-faktor yang Mempengaruhi dan Implikasi Kebijakan Pengembangan Budidayanya, Jurnal Ekonomi Pembangunan, (online) Vol. 10 No.1 hal 95 105.

Walgito, B., 2010. Bimbingan dan Konseling (Studi \& Karir).Yogyakarta : Penerbit CV Andi Offset. 
PS. Agrobisnis Perikanan FPIK UNSRAT

AKULTURASI

Available online :http://ejournal.unsrat.ac.id/index.php/akulturasi

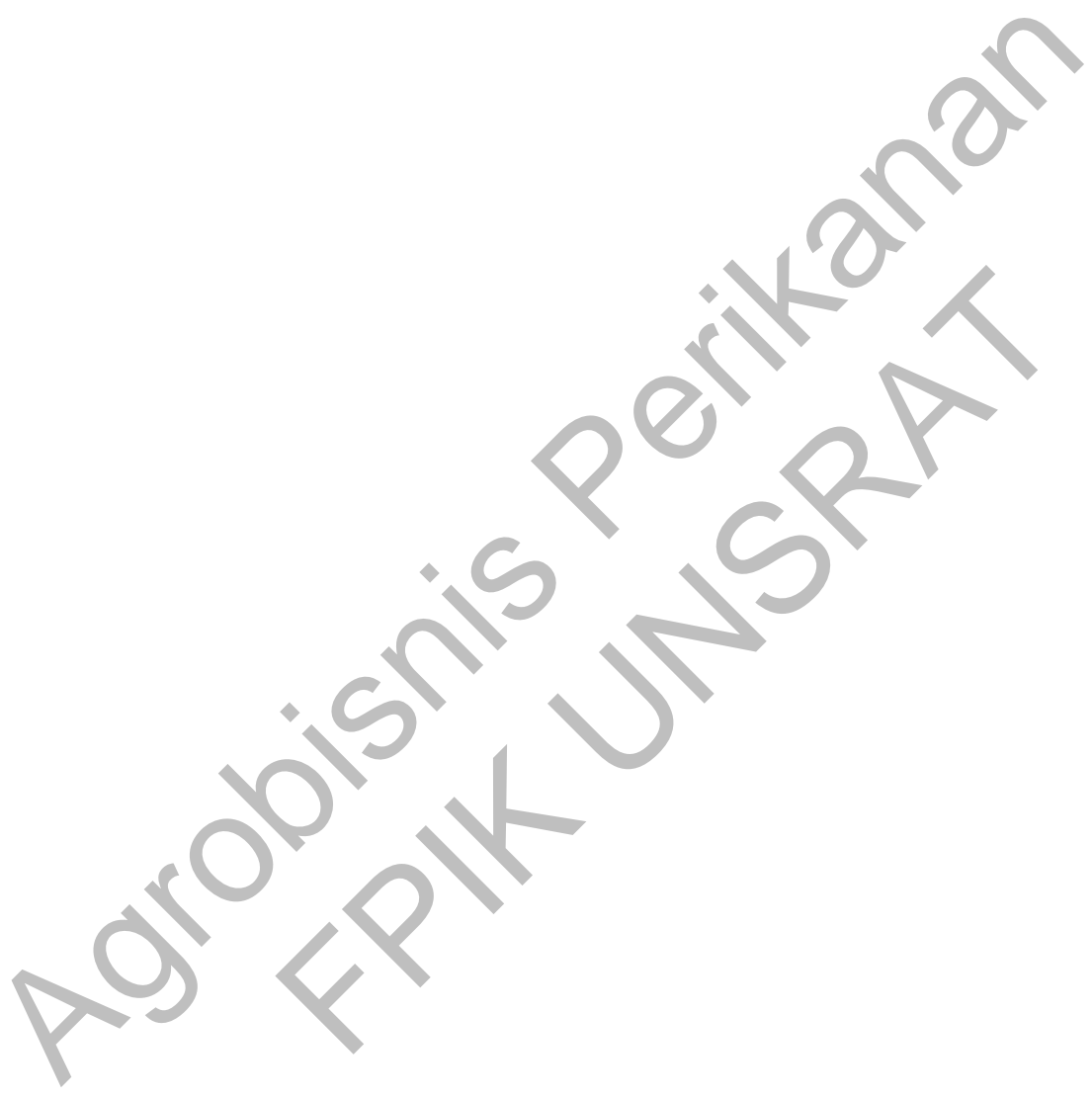

